The Geological Society of America

Special Paper 505

2014

\title{
Calendar-year dating of the Greenland Ice Sheet Project 2 (GISP2) ice core from the early sixth century using historical, ion, and particulate data
}

\author{
Dallas H. Abbott \\ Dee Breger ${ }^{\dagger}$ \\ Pierre E. Biscaye \\ Lamont-Doherty Earth Observatory of Columbia University, Palisades, New York 10964, USA \\ Robert A. Juhl \\ Independent researcher, 1-4-1 Rokko Heights, 906 Shinkawa, Chuo-ku, Tokyo 104-0033, Japan
}

\begin{abstract}
We use the occurrence of unusual or out-of-season dust storms and dissolved ion data as proxies for dust to propose a calendar-year chronology for a portion of the Greenland Ice Sheet Project 2 (GISP2) ice core during the early sixth century A.D. Our new time scale moves a small sulfate peak to early 537 A.D., which is more consistent with recent findings of a 6 mo to 18 mo time lag between volcanic eruptions and atmospheric fallout of their sulfate aerosols. Our new time scale is consistent with a small volcanic input to the A.D. 536-537 climate downturn. We use the time range of Ni-rich fragments and cosmic spherules to provide an independent test of the chronology. The time range of Ni-rich fragments and cosmic spherules matches historical observations of "dancing stars" starting in the summer of A.D. 533 and lasting until A.D. 539 or 540. These dancing stars have been previously attributed to cosmogenic dust loading of Earth's atmosphere. The time scale cannot be shifted to be either younger or older by 1 yr without destroying the match to historical accounts of dancing stars.
\end{abstract}

\section{INTRODUCTION}

The Greenland Ice Sheet Project 2 (GISP2) ice cores from central Greenland are much better dated than those from Antarctica. Errors in dating of the portion of the GISP2 ice core covering the sixth century A.D. are on the order of \pm 3 yr. In contrast, typical errors in dating of Antarctic ice cores are about $\pm 10 \mathrm{yr}$. Because precise chronology is essential to the solution of many geological problems, more accurate dating of ice cores could produce new insights.

In this paper, we discuss a section of the GISP2 ice core that was purposely selected for its potentially high content of

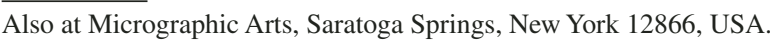

Abbott, D.H., Breger, D., Biscaye, P.E., and Juhl, R.A., 2014, Calendar-year dating of the Greenland Ice Sheet Project 2 (GISP2) ice core from the early sixth century using historical, ion, and particulate data, in Keller, G., and Kerr, A.C., eds., Volcanism, Impacts, and Mass Extinctions: Causes and Effects: Geological Society of America Special Paper 505, p. 411-420, doi:10.1130/2014.2505(22). For permission to copy, contact editing@ geosociety.org. @ 2014 The Geological Society of America. All rights reserved. 
extraterrestrial material (Baillie, 1999). The time period from A.D. 534 to 541 has been the subject of an ongoing controversy about the exact dating of these sections within ice cores from Greenland (Baillie, 2008; Larsen et al., 2008). If we can resolve this controversy for the GISP2 core, it will provide important constraints on the relative importance of volcanic and extraterrestrial drivers for climate downturns during this time period (Rigby et al., 2004; Baillie, 2007).

\section{CHRONOLOGY OF GREENLAND ICE CORES-HOW WELL CAN WE DATE THEM?}

We start with the Meese-Sowers time scale for the GISP2 core (Sowers et al., 1993; Meese et al., 1994a, 1994b). They estimated errors of $\pm 3 \mathrm{yr}$ during the middle of the sixth century. We checked this inference using our ion data from the GISP2 ice core. Larsen et al., (2008) used layer counts and other methods to cross-date three Greenland ice cores: Greenland Ice Core Project (GRIP), North Greenland Ice Core Project (NGRIP), and DYE-3. Within those cores, they found a Tambora-sized sulfate peak for which they estimated an age of 533-534 \pm 2 yr. They also found a larger sulfate peak for which they estimated an age of A.D. $529 \pm 2$. This chronologically earlier sulfate peak is lacking in our time series (Fig. 1), meaning our time series starts at A.D. $530 \pm 2$ or later. Our time series of ion data (Tables 1 and 2) has two moderately large sulfate peaks, one at A.D. $539.2 \pm$ 3 and a second peak at A.D. $543.8 \pm 3$. The older of these sulfate peaks corresponds to the A.D. $533-534 \pm 2$ sulfate peak of Larsen et al. (2008). Within their estimated errors, our older sulfate peak could be as young as A.D. 536, but no younger if Larsen et al. (2008) are correct. Although Larsen et al. (2008) estimated that their absolute ages had errors of only $2 \mathrm{yr}$, another recent paper suggests that their errors are too small by 4-5 yr (Baillie, 2008). We used historical data to support Baillie's inferences, but we find a more modest error of $3 \mathrm{yr}$ in Larson et al.'s ages. This latter age error is consistent with the Meese-Sowers time scale and its error estimates.

Our first historical data set (Table 3) chronicles intense, unusual dust storms recorded in Chinese annals. Dust storms are common in north China in spring, as seen in recently studied Greenland snow at NGRIP (Bory et al., 2003a, 2003b), but much less common in south China. During the period A.D. 500-560, Chinese annals recorded four dust-related events, all of which were unusual in some sense. Table 3 shows the record and notable features associated with each event.

The first three events were considered unusual for the season, having taken place late in the year. And although the 537 event took place "in season," it was considered unusual at the time, in that "yellow ashes rained from a cloudless sky," which is presumably why it was mentioned in the annals. The A.D. 535 and 536 events were also notable for being heavy falls, and the last four events were unusual in having been recorded in southern annals.

High deserts in China are the major source of dust in highaltitude Greenland ice cores (GISP2, DYE3, NGRIP, and GRIP; Biscaye et al., 1997; Bory et al., 2003a, 2003b). The Mg content

TABLE 1. ION DATA FROM THE GISP 2 ICE CORE

\begin{tabular}{|c|c|c|c|c|c|c|}
\hline Sample number & $\mathrm{Na}(\mu \mathrm{g} / \mathrm{L})$ & $\mathrm{K}(\mu \mathrm{g} / \mathrm{L})$ & $\mathrm{Mg}(\mu \mathrm{g} / \mathrm{L})$ & $\mathrm{Ca}(\mu \mathrm{g} / \mathrm{L})$ & $\mathrm{Cl}(\mu \mathrm{g} / \mathrm{L})$ & $\mathrm{SO}_{4}(\mu \mathrm{g} / \mathrm{L})$ \\
\hline $1 \mathrm{~A}$ & 124.9 & 127.1 & 20.8 & 202.8 & 178.5 & 141.3 \\
\hline $1 B$ & 14.2 & 11 & 3.3 & 31.7 & 35.7 & 30.5 \\
\hline 2-S1 & 21.3 & 13.8 & 7.9 & 63.7 & 38.3 & 24.3 \\
\hline 2-S2 & 21.9 & 14.4 & 8.4 & 65.8 & 39.2 & 26.5 \\
\hline 3-S1 & 23 & 19.9 & 5.3 & 54.9 & 49 & 26.1 \\
\hline 3-S2 & 22.5 & 19.9 & 5.4 & 56.7 & 48.7 & 26.1 \\
\hline $4 \mathrm{~A}-\mathrm{S} 1$ & 280.7 & 144.4 & 10.8 & 105.7 & 485.8 & 122.6 \\
\hline 4A-S2 & 307.8 & 168.5 & 12.8 & 126.4 & 413.5 & 107.5 \\
\hline 4B & 24.2 & 26.9 & 6.6 & 80.6 & 102.3 & 81 \\
\hline $4 \mathrm{C}$ & 40.5 & 41.2 & 2.8 & 49.5 & 78.4 & 34.1 \\
\hline $5 A$ & 25.7 & 24.1 & 12.2 & 144.9 & 56.8 & 52 \\
\hline $5 B$ & 38.5 & 22.6 & 14.9 & 236.2 & 63.3 & 86.3 \\
\hline $5 C$ & 269 & 240.1 & 22.8 & 220.8 & 404.3 & 143.3 \\
\hline 6 & 63.4 & 61.3 & 4.4 & 40.6 & 113.8 & 21.9 \\
\hline 7 & 33.5 & 31.7 & 20.4 & 574.8 & 77.6 & 92.9 \\
\hline 8 & 24.4 & 28.1 & 4.7 & 51.2 & 65.7 & 46.5 \\
\hline 9 & 108.2 & 88.9 & 12.7 & 105.1 & 197.8 & 91 \\
\hline $10 \mathrm{~A}$ & 16.2 & 10.6 & 2.9 & 51.5 & 47 & 32.2 \\
\hline $10 \mathrm{~B}$ & 19.4 & 13 & 2.4 & 10.1 & 52.8 & 21.8 \\
\hline $11-S 1$ & 24.4 & 30 & 3.6 & 42.1 & 53.8 & 31.5 \\
\hline $11-S 2$ & 24.2 & 29.6 & 3.8 & 43 & 52.2 & 29.8 \\
\hline $12 \mathrm{~A}$ & 36.5 & 38.2 & 3.6 & 59.8 & 70.8 & 36.1 \\
\hline $12 B$ & 11.8 & 11.5 & 2.7 & 53.7 & 37.3 & 29.1 \\
\hline Blank 1 & 0.4 & 0.3 & 0 & 0.9 & 45.5 & 0 \\
\hline Blank 2 & 0.3 & 0.3 & 0 & 0.8 & 45.6 & 0.7 \\
\hline
\end{tabular}

Note: $\mathrm{Cl}$ values are used to correct for the effects of sea salt on the concentrations of K, Mg, and Ca (Table 2). GISP2-Greenland Ice Sheet Project 2. 
TABLE 2. ION DATA FROM GISP2 ICE CORE

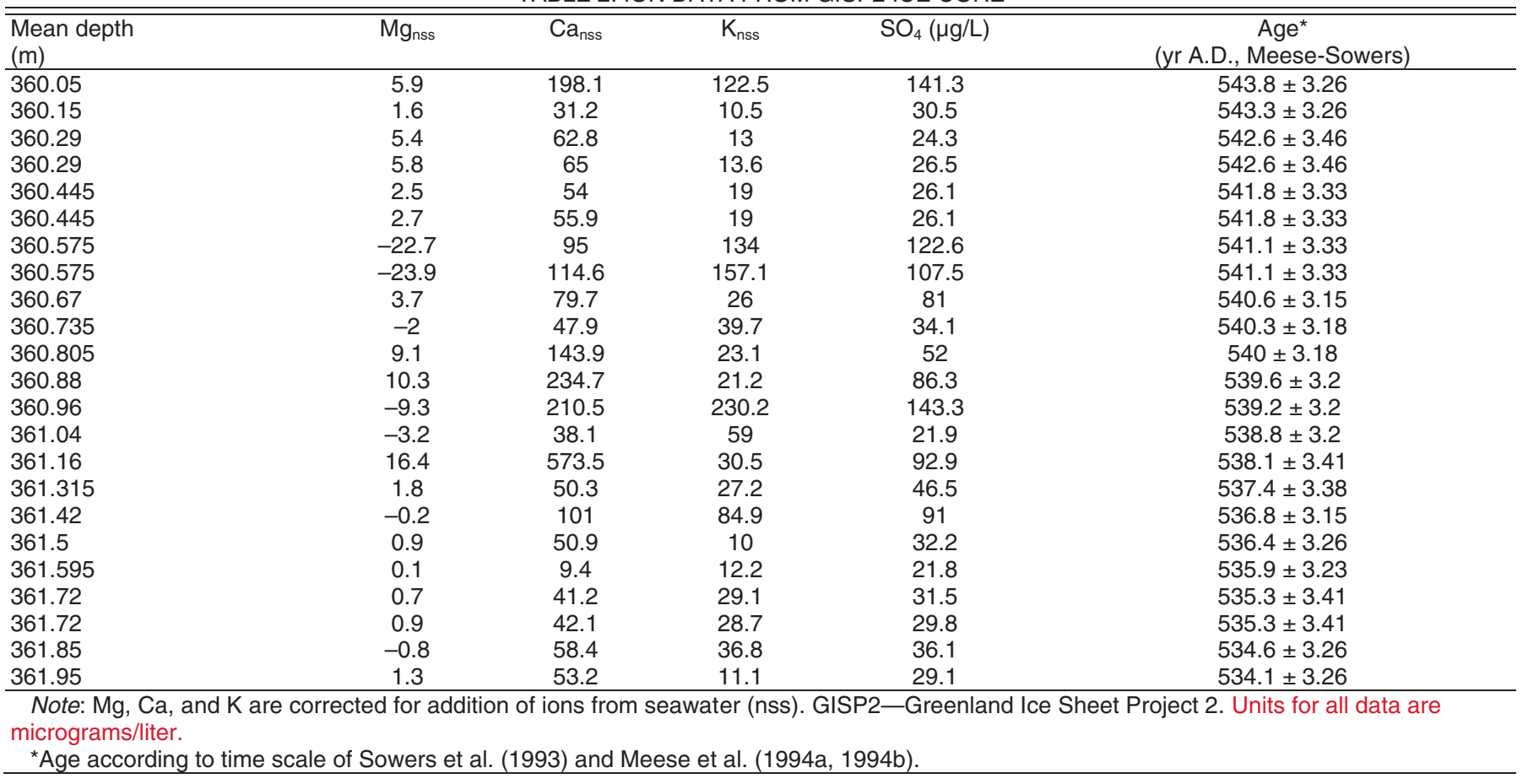

of ice-core meltwater, corrected for the $\mathrm{Mg}$ contribution from seawater salt, is an accepted proxy for continental dust (Kang et al., 2003). Although it is less reliable due to oceanic carbonate sources, the $\mathrm{Ca}$ content, corrected for the $\mathrm{Ca}$ contribution from seawater salt, is also a proxy for continental dust (O'Brien et al., 1995; Zdanowicz et al., 2000). Our ion data show two peaks in $\mathrm{Mg}$ and $\mathrm{Ca}$ that are separated by about a year. If the MeeseSowers time scale is shifted backward by $2 \mathrm{yr}$, the $\mathrm{Ca}$ and $\mathrm{Mg}$ peaks line up with the ages of the recorded dust storms in south China (Fig. 1).

\section{LABORATORY METHODS}

Our ice-core samples were processed under a laminar-flow hood. The hood has a filter and positive pressure that prevent contamination from local dust. The outside surface of each ice-core sample was rinsed with quartz-distilled water to remove contamination from drilling and atmospheric dust. The remaining ice was melted under the laminar-flow hood. We centrifuged the meltwater, and the supernatant was analyzed for ion concentrations using ion chromatography. A large drop of the remaining particulate-rich water was placed inside cleaned Teflon washers glued to cleaned glass slides and left to evaporate in the laminarflow hood. All final cleaning and rinsing was done with quartzdistilled water. Each slide was then covered and subsequently imaged and analyzed using a Zeiss Supra 50 scanning electron microscope (SEM) with attached EDAX energy-dispersive X-ray spectrometer (EDS). Micrographs were collected in secondary electron (SE), backscattered electron (BSE), or mixed SE and BSE modes. Imaging and analyses were conducted in highvacuum mode at $15 \mathrm{kV}$ accelerating voltage. In between SEM sessions, each slide was covered and stored inside the laminarflow hood to prevent contamination from atmospheric dust. Covers were removed immediately prior to SEM/EDS examination and replaced immediately after. Marine-sediment cores were stored in a different building.

TABLE 3. DUST-RELATED EVENTS IN CHINA A.D. 500-560

\begin{tabular}{|c|c|c|}
\hline Date/time frame & Sources* $^{*}$ & Record \\
\hline $\begin{array}{l}\text { Approximately Sep to } \\
\text { mid-Nov } 522\end{array}$ & Wei shu 105, Tianxiang Zhi: 2341 & $\begin{array}{l}\text { N. China: "Since the 8th lunar month ( } 6 \text { Sep-5 Oct } 522 \text { ), yellow dust has hidden } \\
\text { the sun...." [Quote is from a document addressed to the emperor from a minister. } \\
\text { Document is dated } 14 \text { Nov } 522 .]\end{array}$ \\
\hline 11 Nov-9 Dec 535 & Nan shi 7, Liang Benji: 211 & S. China: Winter, 10th month (11 Nov-9 Dec 535). Yellow dust fell like snow. \\
\hline 29 Nov-27 Dec 536 & Nan shi 7, Liang Benji: 212 & $\begin{array}{l}\text { S. China: } 11 \text { th month (29 Nov-27 Dec 536), yellow dust fell like snow. It filled } \\
\text { scoops when picked up. }\end{array}$ \\
\hline 1 Feb 537 & Liang shu 3, Wudixia: 81 & S. China: On 1 Feb 537, the sky was cloudless, but it rained ashes of yellow color. \\
\hline 8 Feb 550 & Nan shi 8, Liang Benji: 230 & S. China: On 8 Feb 550, Yellow sand rained from the sky. \\
\hline
\end{tabular}



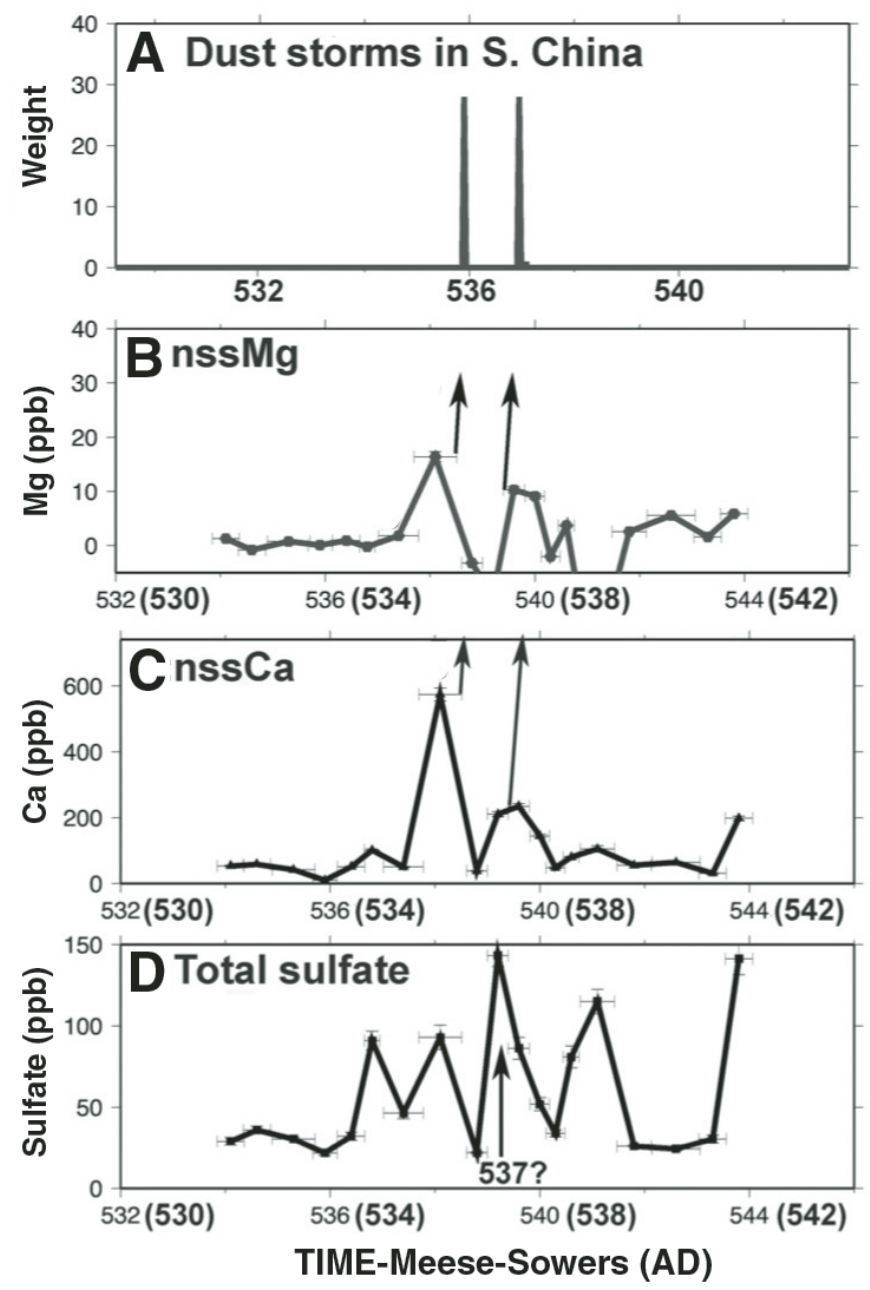

Figure 1. Time series of (A) dust storms in south China and (B-D) ion data from ice-core meltwater in ppb. Absolute ages and relative ages are shown in different fonts and sizes. Smaller numbers - relative ages from the Meese-Sowers time scale. Larger bold numbers - calendar-year age. Bold numbers in parenthesesinferred calendar-year age. (A) Historical time series of dust storms. Each event is plotted as a Gaussian distribution. (B) Ion data, where $\mathrm{nssMg}$ is $\mathrm{Mg}$ corrected for the effect of salt from the ocean. (C) Ion data, where nssCa is $\mathrm{Ca}$ corrected for the effect of salt from the ocean. (D) Total sulfate. The sulfate peak labeled 537? corresponds to the A.D. 533-534 \pm 2 sulfate peak of Larsen et al. (2008).

\section{CHRONOLOGY, ION DATA, AND VOLCANIC HYPOTHESIS FOR THE A.D. 536-537 CLIMATE CATASTROPHE}

Our ion data show two relatively large sulfate peaks, one ca. A.D. 537 and the second ca. A.D. 541-542 (Fig. 1). Both peaks are approximately the same size. This is important, because historical sources indicate that the climate downturn in A.D. 536-537 was far more pronounced than in A.D. 541542. Ancient histories have provided at least four contemporary accounts of a dramatic decrease in the Sun's brightness during A.D. 536 and 537 (Stothers, 1984). In Mesopotamia $\left(30-37^{\circ} \mathrm{N}\right)$, a source later quoted by Michael the Syrian (ca. 1166-1199 A.D.) and Bar-Hebraeus (ca. 1246-1286) stated "In the year 848 of the Greeks [536 A.D.]...the Sun was dark and its darkness lasted for eighteen months, each day it shone for about 4 hours, and still this light was only a feeble shadow... the fruits did not ripen and wine tasted like sour grapes" (translated to English from Chabot [in French], 1901, p. 220-221). According to an anonymous writer in Constantinople $\left(41^{\circ} \mathrm{N}\right)$ (Hamilton and Brooks, 1899, p. 267), associated by tradition with Zacharius of Mytilene, "In the year 14 [536 A.D.]...the Sun began to be darkened by day and the Moon by night... from the $24^{\text {th }}$ of March in this year until the $24^{\text {th }}$ of June in the following year 15." Because the dimming was less severe and shorter in duration (15 mo instead of 18) at higher latitudes, it is generally agreed that the atmosphere was filled with fine dust from an unknown, low-latitude source. Volcanic ash and impact debris are both promoted as the primary sources of that dust (Rigby et al., 2004; Larsen et al., 2008).

These observations are important because the Tambora eruption produced a dim Sun but no reduction in the length of the day (Rampino et al., 1988). In contrast, during the A.D. 536-537 event, the length of the day was reduced to $4 \mathrm{~h}$. Thus, if the sole driver of the A.D. 536-537 climate downturn was sulfate from volcanic sources, the average size of the sulfate peak should be significantly larger than the peak from the Tambora eruption. As observed in Greenland, the A.D. $534 \pm 2$ sulfate peak in three ice cores has the same amplitude as the sulfate peak from the Tambora eruption (Fig. 2).

Our proposed time scale places the same sulfate peak at ca. A.D. 537.2. This is consistent with recent research on the time lag between the deposition of volcanic ash (nearly simultaneous with the eruption) and later deposition of volcanic sulfate (the driver of climate cooling from tropical eruptions). The time lag is between 6 and $18 \mathrm{mo}$, depending on the height of the eruptive column (Koffman et al., 2011). Because ice cores show pronounced seasonal changes in dust deposition and in acidity (Wei et al., 2008), it is relatively easy to estimate the time range covered by individual ice core samples. Based on the depth range of our samples, the ca. A.D. 537 sulfate peak has a proposed age range of ca. A.D. 537-537.4. Using a time lag of 6-18 mo, the source volcanic eruption occurred between A.D. 535.5 and 536.9. Because the A.D. 536-537 climate downturn started in March of A.D. 536, the new time scale is consistent with a small volcanic contribution to the climate cooling.

Although our new time scale is consistent with a volcanic contribution to the A.D. 536 event, the relatively small size of the sulfate peak - similar to that from the Tambora eruptionsuggests that the story is more complicated. As we will show, the ice core contains particles of extraterrestrial provenance. These particles suggest that significant amounts of extraterrestrial dust were falling through Earth's atmosphere during this time. 


\section{EXTRATERRESTRIAL DUST IN THE ICE CORE}

We found two types of debris of possible extraterrestrial origin in the particles from the GISP2 ice core. The first type of material is rich in $\mathrm{Ni}$ and is typically not spherical, although some particles have locally melted surfaces or ablation rinds (Fig. 3). The second type contains Fe-oxide-rich spherules (I-type cosmic spherules; Fig. 4). I-type cosmic spherules contain mainly $\mathrm{FeO}$ with minor amounts of other oxides. Ni-rich iron metal can occur but is usually inside the spherule and would not be detectable using our methodology (Genge et al., 2008). Larger I-type cosmic spherules have visible quench textures on their surfaces. The two types of material have slightly different origins.

Intact fragments of Ni-rich material resemble unmelted or partially melted extraterrestrial debris. Cosmic populations with diameters ranging from 53 to $106 \mu \mathrm{m}$ contain only $\sim 3 \%$ of the expected number of completely melted cosmic spherules (Taylor et al., 2000). The remainder of the material is partially melted and nonspherical. Consequently, individual fragments of extra-

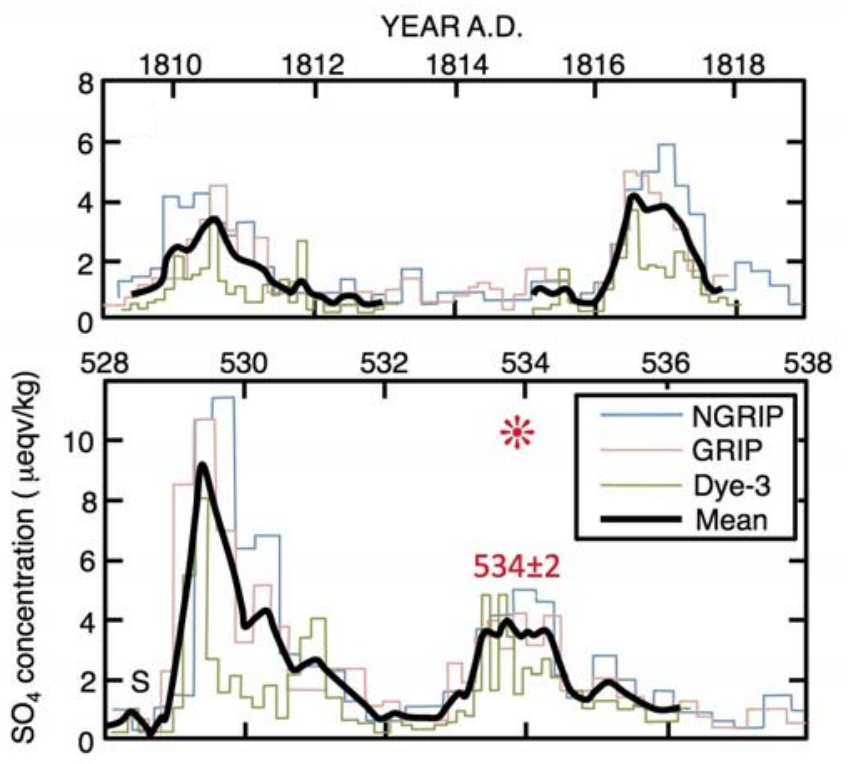

Figure 2. Sulfate $\left(\mathrm{SO}_{4}\right)$ concentration in microequivalents per kilogram $(\mu \mathrm{eqv} / \mathrm{kg})$ in three Greenland ice cores: Greenland Ice Core Project (GRIP), North Greenland Ice Core Project (NGRIP), and DYE-3 (after Larson et al., 2008). (A) A.D. 1809-1819. The Tambora eruption was in April A.D. 1815. The sulfate peak lags the eruption by about a year. The time during which sulfate remains in the atmosphere should match the duration of increased atmospheric dimming and cooling. (B) A.D. 528-538. The sulfate peak is smaller than that from A.D. $529 \pm 2$. In A.D. 530, there is a modest growth reduction recorded by some tree-ring records that is interpreted as a climate downturn (Baillie, 2008). There is no frost ring in bristlecone pines at A.D. 530 (Salzer and Hughes, 2007). The red letters show the suggested dating of the sulfate peak by Larson et al. (2008). The height of the red star is a minimum estimate of the amount of sulfate needed to produce a prominent climate downturn like that during A.D. 536-537. terrestrial material less than $\sim 50 \mu \mathrm{m}$ in diameter are unlikely to completely melt to form cosmic spherules.

Although unmelted Ni-rich particles can arise from a Chelyabinsk-type explosion (Galimov et al., 2013) when a relatively small impactor explodes high in the atmosphere, the maximum diameter of our Ni-rich debris is $24 \mu \mathrm{m}$. These small, sharp-edged fragments do not require a Chelyabinsk-type event to descend to the surface of Earth. Such small fragments often experience some local melting and ablation, as is evidenced by the presence of small spherules on the upper left of the fragment in Figure 3A. Nevertheless, despite a relatively high velocity of entry into Earth's atmosphere (typically $17 \mathrm{~km} / \mathrm{s}$ for asteroidal debris and $51 \mathrm{~km} / \mathrm{s}$ for cometary debris; Collins et al., 2005), these tiny extraterrestrial fragments float down to Earth's surface relatively unaltered.

The second type of particle is cosmic spherules dominantly composed of Fe-oxide. The larger cosmic spherules exhibit quench textures on their surfaces (Figs. 4A and 4C). Fe-rich cosmic spherules are derived from ablation of larger Fe-rich bodies of extraterrestrial origin. When a large extraterrestrial body enters Earth's atmosphere, it is heated by atmospheric friction. As a result, its surface simultaneously melts and ablates. Cosmic spherules spall off the surface of the ablating body. Because they are secondary in origin, these I-type cosmic spherules can be much smaller than sharp-edged Ni-rich fragments. The quench textures on the surfaces of the Fe-rich cosmic spherules require that the spherule was first molten and then rapidly cooled.

Both the cosmic spherules and Ni-rich fragments must have been derived from larger bodies. Because Ni tends to concentrate in nuggets during melting (Borisov and Palme, 1997), the presence of Ni-rich material within a Fe-rich matrix implies a source body that did not experience large-scale melting during atmospheric transit. In contrast, the Fe-oxide-rich cosmic spherules require extensive melting and ablation of their source body. The Fe-oxide-rich cosmic spherules are probably derived from melting and ablation of the edges of larger pieces of extraterrestrial material or from particles with greater momentum for their size. Their apparent lack of $\mathrm{Ni}$ may reflect the low levels of $\mathrm{Ni}$ $(1 \%-2 \%)$ in the fusion crust of meteorites (Fechtig and Utech, 1964; Genge and Grady, 1999), or it may reflect their derivation from an extraterrestrial source body or mineral with only a few percent $\mathrm{Ni}$ (Taylor et al., 2000). Ni contents below $\sim 1 \%-2 \%$ cannot be detected reliably using the EDS X-ray microanalyzer on the SEM.

Both the cosmic spherules and the Ni-rich particles could represent dust derived from recent fragmentation of an extraterrestrial body. Because sharp edges would be smoothed out by intergranular collisions and the solar wind over time, Ni-rich particles with sharp edges are ephemeral features. Our Ni-rich particles are in the group of smaller fragments (less than $\sim 50 \mu \mathrm{m}$ in diameter) that would survive their transit into Earth's atmosphere with no ablation or only modest ablation of their surfaces. In contrast, larger fragments ( $>50 \mu \mathrm{m}$ in diameter) would ablate extensively or completely on transit through Earth's atmosphere. 


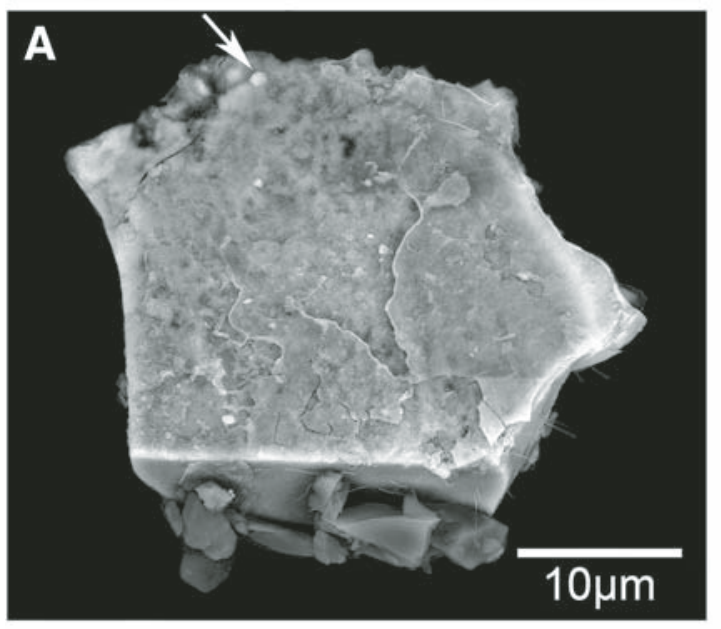

B
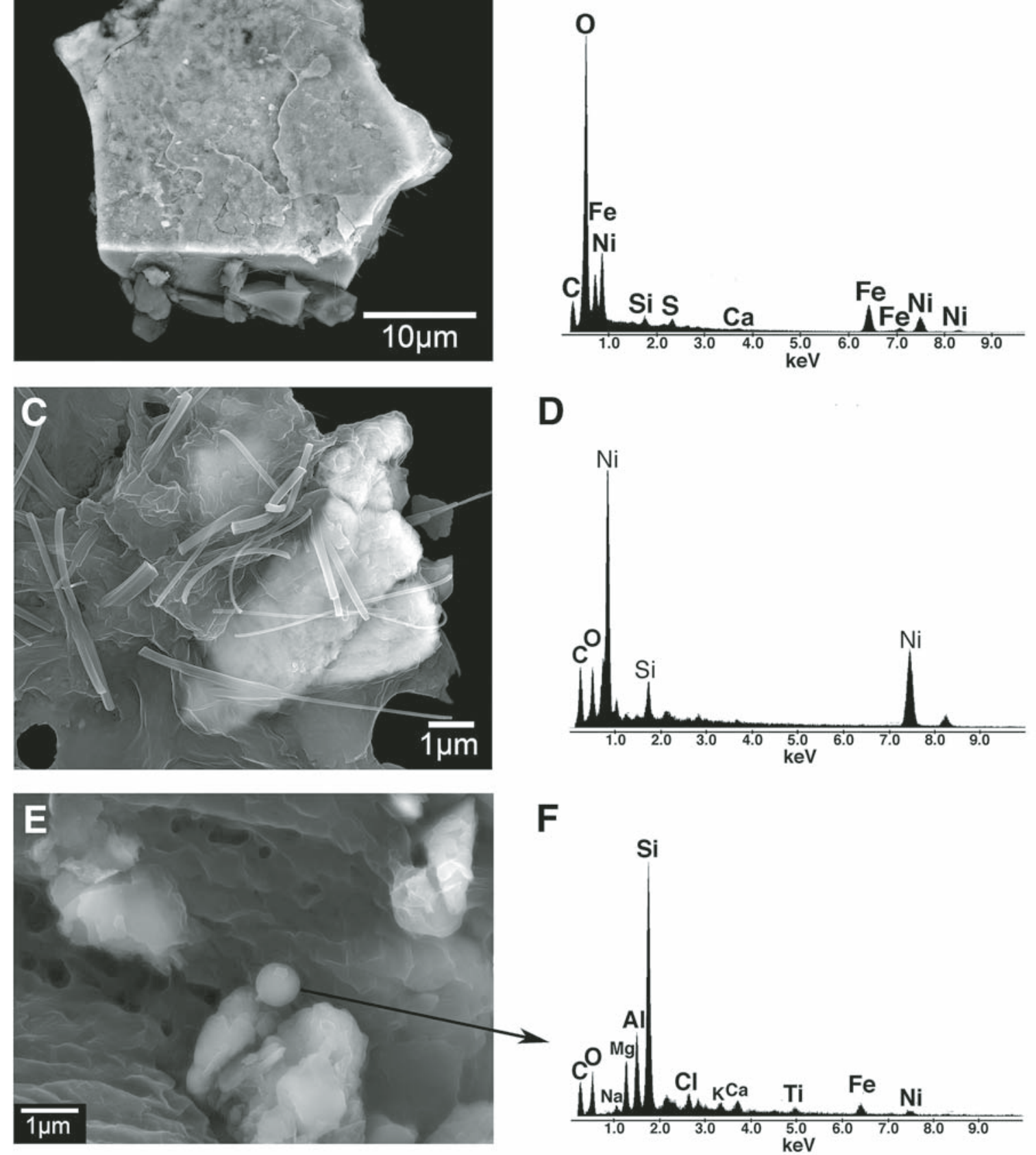

Figure 3. Representative Ni-rich particles from different stratigraphic levels of the Greenland Ice Sheet Project 2 (GISP2) ice core. Left side: Scanning electron microscope (SEM) micrograph. Right side: Qualitative energy-dispersive X-ray spectrometer (EDS) analysis of particle on the left side. (A-B) Arrow points to nucleating ablation spherule on top of Ni-rich particle. This particle contains significant $\mathrm{Fe}, \mathrm{C}, \mathrm{Ca}, \mathrm{S}, \mathrm{O}$, and $\mathrm{Si}$ in addition to Ni. (C-D) Bright particle in micrograph contains $\mathrm{Ni}$ with some $\mathrm{Si}, \mathrm{O}$, and $\mathrm{C}$. The surface fibers are common in uncontaminated, primary samples. Particles interpreted as having surface contamination from brief contacts with the laboratory air during Au-Pd coating and transfer into the SEM do not contain fibers on their surfaces. In some cases, fibers are observed lying underneath the contaminants. (E-F) Arrow points from bright spherule in E to its chemical composition in F. The spherule is mostly $\mathrm{Si}$ but contains $\mathrm{Na}, \mathrm{Mg}, \mathrm{Al}, \mathrm{Cl}, \mathrm{K}, \mathrm{Ca}, \mathrm{Ti}, \mathrm{Fe}$ and $\mathrm{Ni}$. The Ni peak suggests an extraterrestrial component. The $\mathrm{K}$ peak suggests a terrestrial component. Micrograph imaging conditions: (A) 85\% BSE (backscattered electrons), 15\% ILSE (in-lens, secondary electrons); (C) 50\% BSE, 50\% SE2 (secondary electrons); (E) 50\% BSE, 50\% ILSE. (Note that the peak heights are not absolute so no scale is given for peak heights. This means that the relative heights of nearby spectral peaks provide a good estimate of relative abundances of these elements. In contrast, the relative heights of peaks with different energies are only loosely correlated to their relative abundance.) 


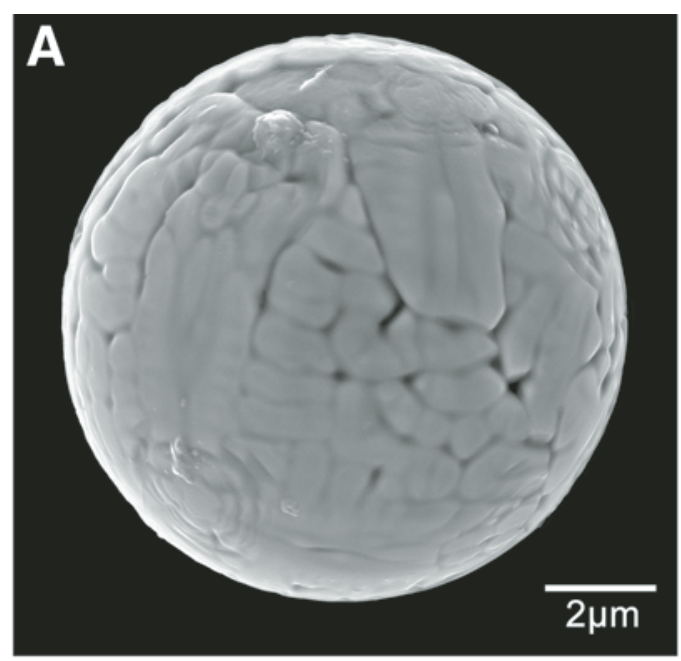

\section{B}
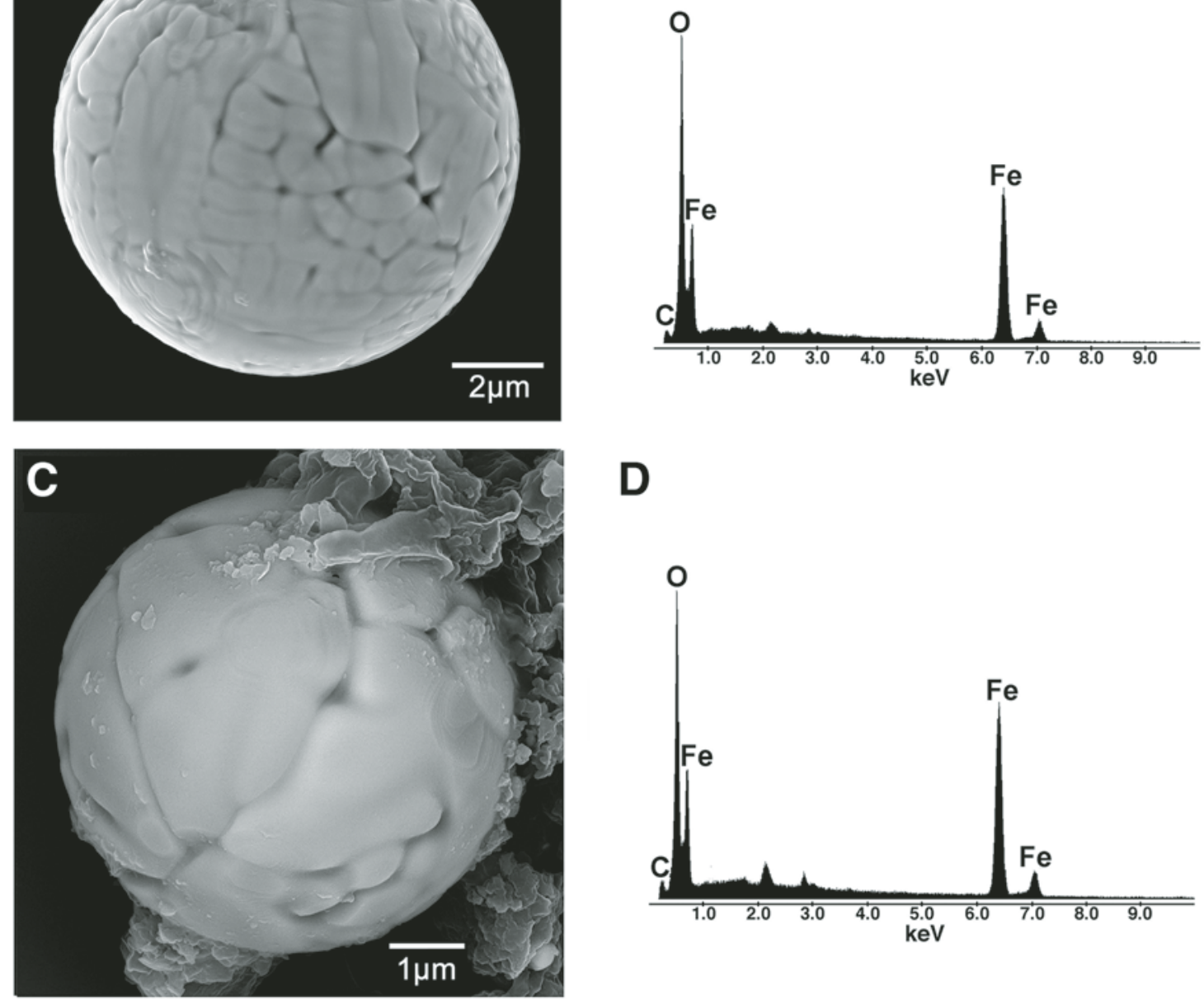

D
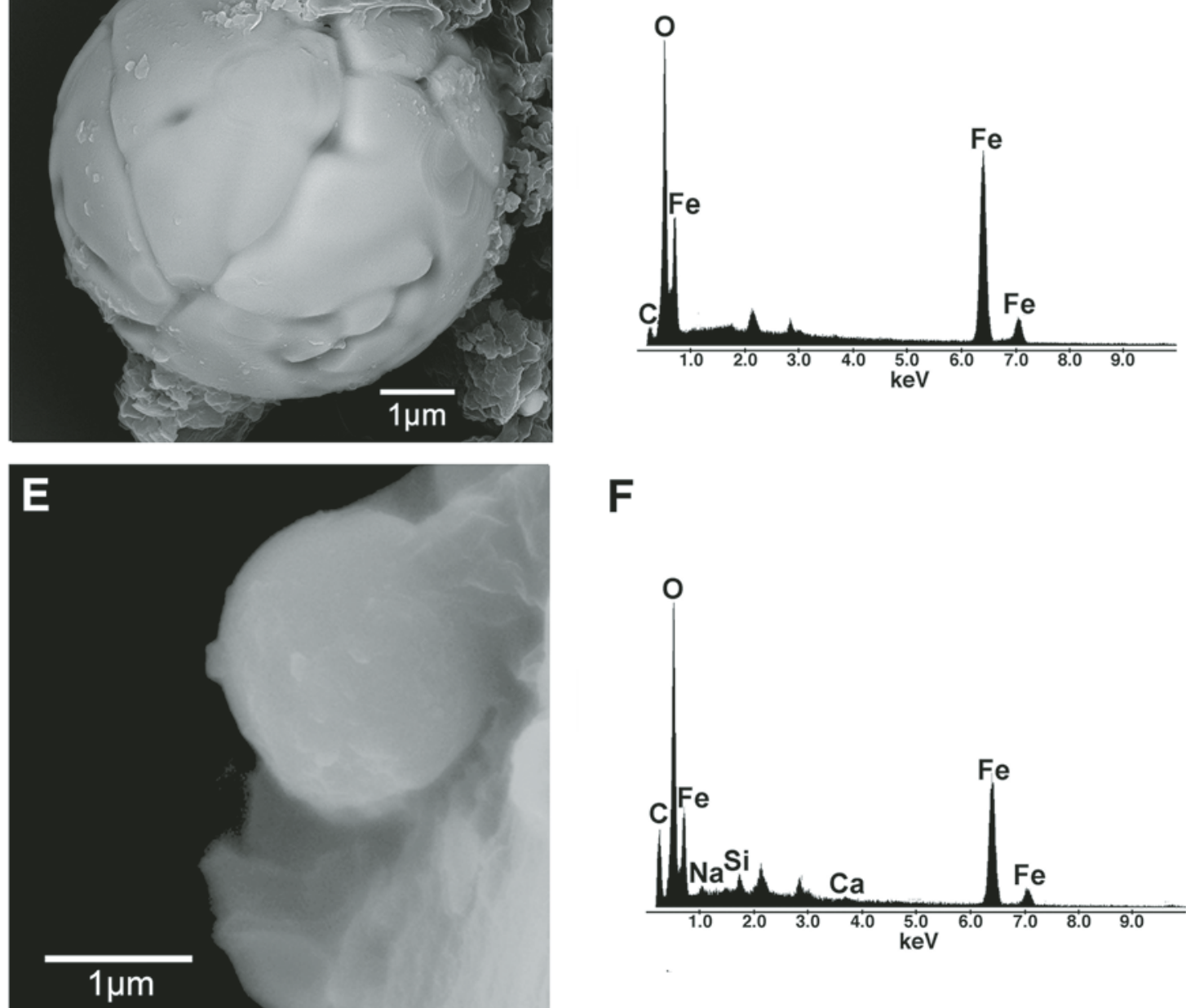

$\mathbf{F}$

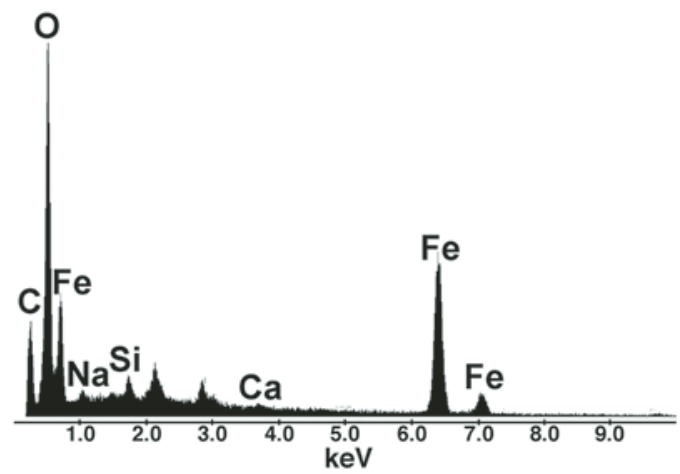

Figure 4. Representative Fe-oxide-rich spherules from different stratigraphic levels of the Greenland Ice Sheet Project 2 (GISP2) ice core. Left: Scanning electron microscope (SEM) micrograph. Right: Qualitative energy-dispersive X-ray spectrometer (EDS) spectrum. Spherules are largely iron oxide with minor C, Mg, Na, and $\mathrm{Si}$ in some cases. Peaks around 2.2 and $2.9 \mathrm{keV}$ are from the Au-Pd coating used to improve the image quality of the SEM micrographs. Micrograph imaging conditions: (A) 80\% ILSE (in-lens, secondary electrons), 20\% BSE (backscattered electrons); (C) 50\% BSE, 50\% SE2 (secondary electrons); (E) 50\% BSE, 50\% ILSE. (Note that the peak heights are not absolute so no scale is given for peak heights. This means that the relative heights of nearby spectral peaks provide a good estimate of relative abundances of these elements. In contrast, the relative heights of peaks with different energies are only loosely correlated to their relative abundance.) 
The melt droplets that spalled off these larger fragments would solidify as Fe-oxide-rich droplets (I-type cosmic spherules.) Unless they were quite large (meters in diameter), these larger fragments would not survive intact to the surface of Earth. Only their cosmic spherules would remain to be incorporated into the geological record. Thus, both the cosmic spherules and the Nirich fragments could have been derived from the same extraterrestrial body.

\section{Independent Test of Chronology from Historical Data}

According to Zacharius of Mytilene "And the stars in the sky had appeared dancing in a strange manner and it was the summer of the year eleven" (A.D. 533; Hamilton and Brooks, 1899, p. n240); "And it lasted about 6 or 7 years, until the year three" (A.D. 540; Hamilton and Brooks, 1899, p. n240). This observation has been interpreted by Baillie as a sign of increased cosmic dust loading of Earth's atmosphere between A.D. 533 and 540 (Baillie, 1999).

Two A.D. 533 celestial events recorded in a north Chinese historical record may reinforce Zacharias' observation. Both suggest a soupy or hazy atmosphere.

(1) "On 15 Oct 533, Mars and Jupiter were in conjunction about one inch apart near alpha Crateris. Their rays covered one another" (Ershisishi: dianjiaoben [all further references to Ershisishi: dianjiaoben] Weishu 105-1 Tianxiangzhi 4: 2445). In other words, the night sky was so hazy that bright objects appeared to project long rays (554).

(2) "On 1 Nov 533, Venus and Mars were in conjunction, 7 inches apart, near gamma Corvi; their rays reached to one another" (Weishu 105-1 Tianxiangzhi 4: 2445).

In addition, there is the account of Cassiodorus in Italy, which was grouped with the A.D. 536 event by Stothers (1984). "The sun...seems to have lost its wonted light, and appears to be of a bluish color. We marvel to see no shadows of our bodies at noon, to feel the mighty vigor of the sun's heat wasted into feebleness, and the phenomena that accompany an eclipse prolonged through almost a whole year. We have had .... a summer without heat ... the crops have been chilled by north winds... the rain is denied" (Barnish, 1992, p. 179). According to Ruggini as quoted by Barnish, this account dates to the late spring of A.D. 534.

If increased cosmic dust produced atmospheric dimming, our observed fluxes of extraterrestrial material should be high compared to the average flux during the Holocene. The average rate of deposition of meteoritic smoke at high latitudes during the Holocene was $78 \pm 30$ metric tons/yr extrapolated over the entire Earth's surface (Gabrielli et al., 2004). (The average Holocene flux at low latitudes extrapolated over the entire Earth's surface is lower; $15 \pm 4$ metric tons/yr.) When the high-latitude flux is converted to volume per unit area using an average particle density of $3.0 \mathrm{~g} / \mathrm{cm}^{3}$, this translates into a flux range of $3.1 \mathrm{E}-9$ to $7.1 \mathrm{E}-9 \mathrm{~cm}^{3} / \mathrm{cm}^{2} / y$. Each of our ice-core samples represents the flux over about $1 \mathrm{~cm}^{2}$ of the surface area of Earth. If we take the stratigraphic level with the largest extraterrestrial particles (one example is in Fig. 3A), it has a total volume of $2.73 \mathrm{E}-8$ $\mathrm{cm}^{3}$. Corrected for the time range covered by this level ( $\left.0.82 \mathrm{yr}\right)$, this represents between 5 and 11 times the average Holocene flux of meteoritic smoke per square centimeter at high latitudes of Earth. This is a minimum calculation, as we cannot include extraterrestrial particles below a few microns in diameter. Thus, the flux of extraterrestrial material into one level of the ice core appears to have been significantly higher than the average flux at high latitudes.

Using our new time scale, our observations of Ni-rich fragments and cosmic spherules in the ice core also extend over this time period (Fig. 5). The oldest Ni-rich fragments are dated as A.D. $533.3 \pm 0.41$. The youngest cosmic spherule is dated as A.D. $539.1 \pm 0.33$. If these dates were shifted to be older by $1 \mathrm{yr}$, the time range of cosmic input would be A.D. 532-538. This is inconsistent with the historical data. If these dates were shifted to be younger by $1 \mathrm{yr}$, the time range with errors would encompass the end of A.D. 533 (i.e., A.D. 533.89) to the start of 540 A.D. Because the dancing of the stars started in the summer of A.D. 533, we cannot shift the time scale to be 1 yr younger. Our calendar-year time scale is the only allowable match.

\section{Suggestions for Further Work}

Our dating can be further tested by examining the GISP2 core for the chemical record of unusual, or out-of-season dust storms, as expressed in $\mathrm{Mg}$ and $\mathrm{Ca}$ ion data corrected for the signal from seawater. There were unusual dust storms in A.D. 522 and in A.D. 550. Other than the dust storms in A.D. 535, 536, and 537 , these are the only unusual dust storms documented between

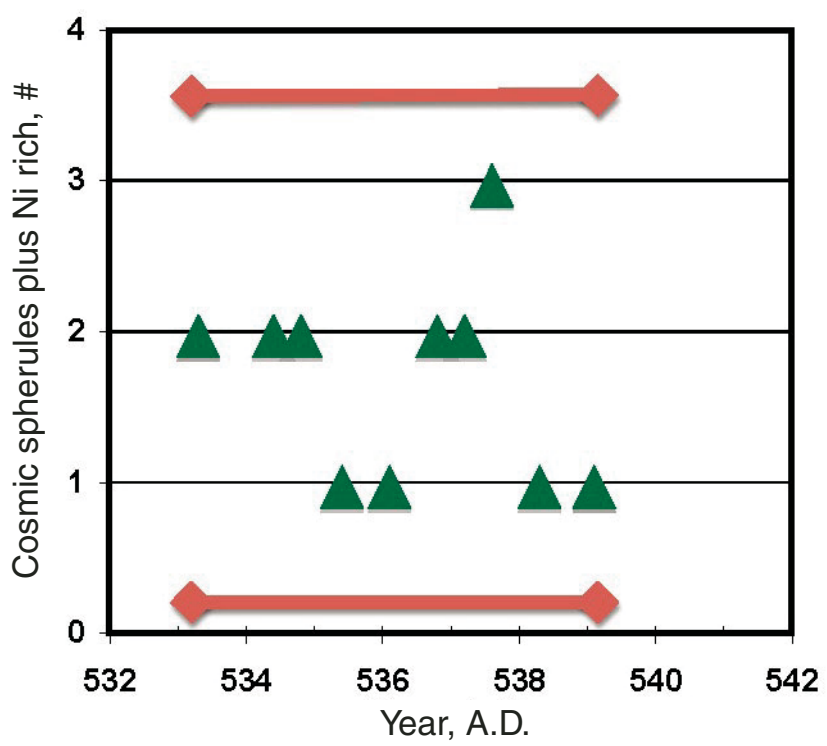

Figure 5. Proposed calendar-year time scale and the occurrence of dancing stars. Green triangles-numbers of Ni-rich fragments and cosmic spherules versus time. Red lines with diamonds on end-Time range of historical observations of dancing stars. 
A.D. 500 and 560. Although a complete scan is not available to us at present, it is possible that a decomposition of color scans of archived ice from the GISP2 core might produce peaks in yellow. If so, color scans coupled with historical data could provide a nondestructive method of dating and cross correlation of highaltitude ice cores from Greenland.

Although the $\mathrm{Mg}$ and $\mathrm{Ca}$ signal from dust storms in central Asia is not present in Antarctica, cosmic dust loading should be planetwide. Thus, Ni-rich particles and cosmic spherules are likely to be present in high-altitude ice cores from Antarctica. These particles could be searched for directly using an SEM and EDS analyzer, or they could be assessed indirectly by measuring the flux of meteoritic smoke (Gabrielli et al., 2004; Lanci and Kent, 2006).

\section{CONCLUSIONS}

Historical accounts of unusual dust storms in China, coupled with ion data, offer a method for calendar-year dating the GISP2 ice. This time scale meets a test based on an independent assessment of the load of Ni-rich particulates and cosmic spherules during this time. This time scale could be further tested by looking at longer time series of ion and particulate data and by color decompositions of color scans of the corresponding sections of ice cores. Our methods offer a potentially powerful tool for refining the dating of both Greenland and Antarctic ice cores.

\section{ACKNOWLEDGMENTS}

We thank Jihong Cole-Dai for the ion data on our supernatant water samples. We are grateful to the Lamont-Doherty Earth Observatory Climate Center for their support of our laboratory and analytical costs. This work would have been impossible without their generous support and encouragement. We thank Norm Sleep and Michael Ram for helpful reviews. We thank the Electron Microscopy Center at The City College of New York for access to their facilities.

\section{REFERENCES CITED}

Shu, Tianxiangzhi, 554, Wei Shou, editor, tianxiangzhi (History of the Wei Dynasty, Celestial Phenomena): Ershisishi, dianjiaoben, 1962-75 [The 24 standard dynastic histories, punctuated and collated; 241 volume sets]: Beijing, Zhonghua Book Company (Zhonghua Shuju) [in Chinese] (all Chinese references in this chapter are to Ershisishi: dianjiaoben).

Baillie, M.G., 1999, Exodus to Arthur: Catastrophic Encounters with Comets: London, UK, Batsford, $256 \mathrm{p}$.

Baillie, M.G.L., 2007, Tree-rings indicate global environmental downturns that could have been caused by comet debris, in Bobrowsky, P.T., and Rickman, H., eds., Comet/Asteroid Impacts and Human Society: Berlin, Springer, p. 105-122.

Baillie, M.G.L., 2008, Proposed re-dating of the European ice core chronology by seven years: Geophysical Research Letters, v. 35, p. L15813, doi:10.1029/12008GL034755.

Bar-Hebraus, [ca. 1246-1286], 1932, Chronography (translated by Budge, E.A.W.): London, Oxford University Press.

Barnish, S.J.B., 1992, The Variae of Magnus Aurelius Cassiodorus Senator: Liverpool, UK, Liverpool University Press, 254 p.
Biscaye, P., Grousset, E.E., Revel, M., Gaast, S.V., Zielinski, G.A., Vaars, A., and Kukla, G., 1997, Asian provenance of glacial dust (stage 2) in the Greenland Ice Sheet Project 2 core, Summit, Greenland: Journal of Geophysical Research, v. 102, p. 26,765-26,781.

Borisov, A., and Palme, H., 1997, Experimental determination of the solubility of platinum in silicate melts: Geochimica et Cosmochimica Acta, v. 61, p. 4349-4357, doi:10.1016/S0016-7037(97)00268-8.

Bory, A.J.-M., Biscaye, P.E., and Grousset, F.E., 2003a, Two distinct seasonal Asian source regions for mineral dust deposited in Greenland (NorthGRIP): Geophysical Research Letters, v. 30, p. 1167, doi:10 .1029/2002GL016446

Bory, A.J.-M., Biscaye, P.E., Piotrowski, A.M., and Steffensen, J.P., 2003b, Regional variability of ice core dust composition and provenance in Greenland: Geochemistry Geophysics Geosystems, v. 4, no. 12, p. 1107, doi:1110.1029/2003GC000627.

Collins, G.S., Melosh, H.J., and Marcus, R.A., 2005, Earth Impact Effects Program: A Web-based computer program for calculating the regional environmental consequences of a meteoroid impact on Earth: Meteoritics \& Planetary Science, v. 40, p. 817-840, doi:10.1111/j.1945-5100.2005.tb00157.x.

Fechtig, H., and Utech, K., 1964, On the presence or absence of nickel in dark magnetic cosmic spherules and their mechanics of origin: Annals of the New York Academy of Sciences, v. 119, p. 243-249, doi:10.1111/j.1749-6632.1965.tb47437.x.

Gabrielli, P., Barbante, C., Plane, J.M., Varga, A., Hong, S., Cozzi, G., Gaspari, V., Planchon, F.M., Cairns, W., Ferrari, C., Crutzen, P., Cescon, P., and Boutron, C.F., 2004, Meteoric smoke fallout over the Holocene Epoch revealed by iridium and platinum in Greenland ice: Nature, v. 432 , p. 1011-1014, doi:10.1038/nature03137.

Galimov, E.M., Kolotov, V.P., Nazarov, M.A., Kostitsyn, Yu. A., Kubrakova, I.V., Kononkova, N.N., Roshchina, I.A., Alexeev, V.A., Kashkarov, L.L., Badyukov, D.D., and Sevast'yanov, V.S., 2013, Analytical results for the material of the Chelyabinsk meteorite: Geochemistry International, v. 51, p. 522-539.

Genge, M.J., and Grady, M.M., 1999, The fusion crusts of stony meteorites: Implications for the atmospheric reprocessing of extraterrestrial materials: Meteoritics \& Planetary Science, v. 34, p. 341-356, doi:10.1111/j.1945-5100.1999.tb01344.x.

Genge, M.J., Engrand, C., Gounelle, M., and Taylor, S., 2008, The classification of micrometeorites: Meteoritics \& Planetary Science, v. 43, p. 497-515, doi:10.1111/j.1945-5100.2008.tb00668.x.

Hamilton, F.J., and Brooks, E.W., 1899, The Syriac Chronicle Known as that of Zachariah of Mitylene: London, UK, Methuen and Co., Byzantine Texts, p. 24-37.

Kang, S., Mayewski, P.A., Yan, Y., Qin, D., Yao, T., and Ren, J., 2003, Dust records from three ice cores: Relationships to spring atmospheric circulation over the Northern Hemisphere: Atmospheric Environment, v. 37, p. 4823-4835, doi:10.1016/j.atmosenv.2003.08.010.

Koffman, B.G., Kreutz, K.J., Breton, D.J., Dunbar, N.W., and Kurbatov, A., 2011, Depositional phasing of volcanic aerosols in the WAIS Divide ice core over the past 2400 years: Washington, DC, American Geophysical Union, Fall Meeting, abstract V11D-2539.

Lanci, L., and Kent, D.V., 2006, Meteoric smoke fallout revealed by superparamagnetism in Greenland ice: Geophysical Research Letters, v. 33, doi:10.1029/2006GL026480.

Larsen, L.B., Vinther B.M., Briffa, K.R., Melvin, T.M., Clausen, H.B., Jones, P.D., Siggard-Anderson, M.-L., Hammer, C.U., Eronen, M., Grudd, H., Gunnarson, B.E., Hantemirov, R.M., Naurzbaev, M.N., and Nicolussi, K., 2008, New ice core evidence for a volcanic cause of the A.D. 536 dust veil: Geophysical Research Letters, v. 35, p. L04708, doi:10.1029/02007GL032450.

Li Yanshou, editor, 650, Nan shi, Liangbenji (History of the Southern Dynasties, Records of the Liang Dynasty): Ershisishi, dianjiaoben, 1962-75 [The 24 standard dynastic histories, punctuated and collated; 241 volume sets]: Beijing, Zhonghua Book Company (Zhonghua Shuju) [in Chinese]

Meese, D.A., Gow, A.J., Grootes, P.M., Mayewski, P.A., Ram, M., Stuiver, M., Taylor, K.C., Waddington, E.D., and Zielinski, G.A., 1994, The accumulation record from the GISP2 core as an indicator of climate change throughout the Holocene: Science, v. 266, p. 1680-1682, doi:10.1126/ science.266.5191.1680.

Meese, D.A., Gow, A.J., Alley, R.B., Zielinski, G.A., Grootes, P.M., Ram, M., Taylor, K.C., Mayewski, P.A., and Bolzan, J.F., 1997, The Greenland Ice 
Sheet Project 2 depth-age scale: Methods and results: Journal of Geophysical Research, v. 102, no. C12, p. 26,411-26,423, doi:10.1029/97JC00269.

Michael the Syrian, [ca. 1166-1199 A.D.], 1901, Michael the Syrian Chronicle (translated to French by Chabot, J.-B.): Paris, Belles-Lettres.

O'Brien, S.R., Mayewski, P.A., Meeker, L.D., Meese, D.A., Twickler, M.S., and Wicklow, S.I., 1995, Complexity of Holocene climate as reconstructed from a Greenland ice core: Science, v. 270, p. 1962-1964, doi:10.1126/ science.270.5244.1962.

Rampino, M.R., Self, S., and Stothers, R.B., 1988, Volcanic winters: Annual Review of Earth and Planetary Sciences, v. 16, p. 73-99, doi:10.1146/ annurev.ea.16.050188.000445.

Rigby, E., Symonds, M., and Ward-Thompson, D., 2004, A comet impact in AD536?: Astronomy and Geophysics, v. 45, p. 1.23-21.26.

Salzer, M.W., and Hughes, M.K., 2007, Bristlecone pine tree rings and volcanic eruptions over the last 5000 yr: Quaternary Research, v. 67, p. 57-68, doi:10.1016/j.yqres.2006.07.004.

Sowers, T., Bender, M., Labeyrie, L., Martinson, D., Jouzel, J., Raynaud, D., Pichon, J.J., and Korotkevich, Y.S., 1993, A 135,000 year Vostok-SPECMAP common temporal framework: Paleoceanography, v. 8, p. 737-766, doi:10.1029/93PA02328.
Stothers, R.B., 1984, Mystery cloud of AD536: Nature, v. 307, p. 344-345, doi:10.1038/307344a0.

Taylor, S., Lever, J.H., and Harvey, R.P., 2000, Numbers, types, and compositions of an unbiased collection of cosmic spherules: Meteoritics \& Planetary Science, v. 35, p. 651-666, doi:10.1111/j.1945-5100.2000.tb01450.x.

Wei, L., Mosley-Thompson, E., Gabrielli, P., Thompson, L.G., and Barbante, C., 2008, Synchronous deposition of volcanic ash and sulfate aerosols over Greenland in 1783 from the Laki eruption (Iceland): Geophysical Research Letters, v. 35, p. L16501, doi:10.1029/2008GL035117.

Yao Cha and Yao Silian, editors, 635, Liang shu, wudiji (History of the Liang Dynasty, Records of Emperor Wudi): Ershisishi, dianjiaoben, 1962-75 [The 24 standard dynastic histories, punctuated and collated; 241 volume sets]: Beijing, Zhonghua Book Company (Zhonghua Shuju) [in Chinese].

Zdanowicz, C.M., Zielinski, G.A, Wake, C.P., Fisher, D.A., and Koerner, R.M., 2000, A Holocene record of atmospheric dust deposition on the Penny Ice Cap, Baffin Island, Canada: Quaternary Research, v. 53, p. 62-69, doi:10.1006/qres.1999.2091.

ManuscriPt ACCePted by the Society 31 January 2014 